1 Mitchell AJ, Lawrence D. Revascularisation and mortality rates following acute coronary syndromes in people with severe mental illness: comparative meta-analysis. Br J Psychiatry 2011; 198: 434-41.

2 Fox KA, Poole-Wilson PA, Henderson RA, Clayton TC, Chamberlain DA, Shaw $\mathrm{TR}$, et al. Interventional versus conservative treatment for patients with unstable angina or non-ST-elevation myocardial infarction: the British Heart Foundation RITA 3 randomised trial. Randomized Intervention Trial of unstable Angina. Lancet 2002; 360: 743-51.

3 Holmes Jr DR, Kereiakes DJ, Garg S, Serruys PW, Dehmer GJ, Ellis SG, et al. Stent thrombosis. J Am Coll Cardiol 2010; 56: 1357-65.

4 Daemen J, Wenaweser P, Tsuchida K, Abrecht L, Vaina S, Morger C, et al. Early and late coronary stent thrombosis of sirolimus-eluting and paclitaxeleluting-stents in routine clinical practice: data from a large two-institutional cohort study. Lancet 2007; 369: 667-78.

5 Julius RJ, Novitsky Jr MA, Dubin WR. Medication adherence: a review of the literature and implications for clinical practice. J Psychiatr Pract 2009; 15: 34-44.

Scot A. Garg, consultant cardiologist, East Lancashire NHS Trust, UK. Email: scotgarg@hotmail.com; Shruti Garg, ST6 in child and adolescent psychiatry, Central Manchester University Hospitals NHS Foundation Trust, UK

doi: 10.1192/bjp.199.3.252a

Authors' reply: We thank Drs Garg \& Garg for their insightful comments from a cardiologist's perspective. The purpose of our paper was in part to stimulate others to examine more precisely what factors underlie these apparent deficits in received cardiac care. Garg \& Garg raise two issues that we agree deserve further investigation - consent to undertake invasive procedures, and compliance with follow-up care. Regarding consent, we are not aware of any studies on refusal of medical procedures particularly following on from an acute psychiatric episode. However, there are some data on refusal to start medication in psychiatric settings which may be a useful point of comparison. ${ }^{1,2}$ Kasper et al found that in newly admitted psychiatric in-patients $12.9 \%$ refused treatment but that $90 \%$ of these ended their refusal within 4 days suggesting persistent refusal may be overestimated, accounting for perhaps $1 \%$ of treatment problems. ${ }^{2}$ It is worth noting that non-adherence rates among patients with severe mental illness is probably lower for hypoglycaemic and antihypertensive drugs than for antipsychotics. ${ }^{3}$ One important question here is whether the very small proportion of patients who cannot initially consent because of acute mental illness are always given a second chance to consent once well? Better links between physicians and psychiatrists would no doubt help here. Even in those with mental ill health, the vast majority of problems with day-to-day adherence are caused by accidental omissions and rational non-adherence and not ongoing florid psychiatric illness. ${ }^{4}$

The second issue raised was provider caution owing to the possibility of future non-adherence. Garg \& Garg rightly highlight that non-adherence to cardiovascular medication is sometimes higher in those with mental ill health, although this is not always the case. Contrary to popular opinion, non-adherence (to medical drugs) is sometimes lower, not higher, in people with mental illness. ${ }^{5}$ In truth, we do not know whether there is a low prescribing rate or a low uptake rate or both. Focusing on antiplatelet drugs, an unpublished meta-analysis presented by Mitchell at the Royal College of Psychiatrists' Faculty of Liaison Faculty Meeting (2011) found no difference in receipt of antiplatelet drugs in those with $v$. without broadly defined mental illness, but there was a slight effect in those with severe mental illness $(\mathrm{OR}=0.91$, 95\% CI 0.84-0.99), suggesting that patients with severe mental illness are indeed receiving slightly less medication for cardiovascular indications. A caution is that these studies are based on prescribed medication rates not actual adherence with medication.
Documenting these inequalities is only the initial step. Are we taking appropriate actions to compensate for these difficulties? For instance, we would not consider a patient with visual impairment to be non-adherent because they cannot read a patient instruction sheet. We would make extra effort to give the information in another format. Surely, where medical treatment is indicated, we (i.e. all healthcare professionals) must make some effort to compensate for the difficulties faced by patients with comorbid conditions and ensure our facilities and treatments are acceptable and understandable even when it is expensive or inconvenient to do so. Collaborative care, attached professionals and peer-support models have shown promise in some areas. Could cardiologists and psychiatrists working together establish whether these are useful in the aftercare of patients with mental ill health who require cardiac surgery?

1 Baker JA, Bowers L, Owiti JA. Wards features associated with high rates of medication refusal by patients: a large multi-centred survey. Gen Hosp Psychiatry 2009; 31: 80-9.

2 Kasper JA, Hoge SK, Feucht-Haviar T, Cortina J, Cohen B. Prospective study of patients? refusal of antipsychotic medication under a physician discretion review procedure. Am J Psychiatry 1997; 154: 483-9.

3 Piette JD, Heisler M, Ganoczy D, McCarthy JF, Valenstein M. Differential medication adherence among patients with schizophrenia and comorbid diabetes and hypertension. Psychiatr Serv 2007; 58: 207-12.

4 Mitchell AJ, Selmes T. Why don't patients take their medicine? Reasons and solutions in psychiatry. Adv Psychiatr Treat 2007; 13: 336-46.

5 Kreyenbuhl J, Dixon LB, McCarthy JF, Soliman S, Ignacio RV, Valenstein M. Does adherence to medications for type 2 diabetes differ between individuals with vs without schizophrenia? Schizophr Bull 2010; 36: 428-35.

Alex J. Mitchell, Department of Liaison Psychiatry, Leicestershire Partnership Trust and Department of Cancer Studies and Molecular Medicine, Leicester Royal Infirmary, Leicester, UK. Email: ajm80@le.ac.uk; David Lawrence, Telethon Institute for Child Health Research, Centre for Child Health Research, The University of Western Australia, Perth, Australia

doi: 10.1192/bjp.199.3.253

\section{Generalised spike-and-slow-wave complexes without seizures in schizophrenia}

There has been long discussion about the increased prevalence of electroencephalogram (EEG) abnormalities and their significance in patients with schizophrenia. ${ }^{1-4}$ Although interictal epileptiform discharges presumably indicate a higher risk for seizures, ${ }^{5}$ such abnormalities alone in a clinical case of schizophrenia are generally not regarded as having strong implications for antipsychotic therapy.

Here, we report the case of a 17 -year-old student who over a period of several months developed a paranoid-hallucinatory syndrome, feeling persecuted, sidelined and out-casted by his peers. He also experienced changes in auditory perception, reported supersensitive hearing and auditory hallucinations of backbiting whispering voices of his peers. There was a prodromal phase with increasing social withdrawal, affective flattening and a drop in school grades over a period of 2 years prior to the diagnosis of schizophrenia by an out-patient psychiatrist. Treatment with $250 \mathrm{mg}$ quetiapine led to some improvement but not remission. Aged 13 he had been in a road traffic accident, with subtle contusions and subarachnoid bleeding which fully recovered without any other neurological, psychiatric, cognitive or magnetic resonance imaging symptoms or signs. A routine clinical EEG showed infrequent $3 \mathrm{~Hz}$ spike-and-slow-wave complexes (SWCs). Video telemetry for 3 days clearly showed $3 \mathrm{~Hz}$ SWCs with a duration of between 200 and $3500 \mathrm{msec}$ and an average frequency of about 8 per hour and a peak frequency of 18 per hour without clinical seizure correlates. Assuming 
that the EEG findings might play a role in the genesis of schizophreniform syndrome, medication was changed to valproate monotherapy. This resulted in full clinical and cognitive remission and considerable improvement of the EEG within a few weeks. Subsequently, the patient's school grades returned to top levels.

The clinical relevance of such an EEG finding in a patient with schizophrenia is still an unresolved question. ${ }^{6}$ In spite of an intensive historical discussion of this issue, to our knowledge this is the first description of a clinical case of schizophrenia with generalized $3 \mathrm{~Hz}$ SWCs and excellent clinical response to valproate monotherapy. In our view, this case illustrates three clinically important points: (1) it is worthwhile doing EEG studies in patients with schizophrenia; (2) non-ictal SWCs might play a pathogenetic role in a small subgroup of patients with schizophrenia; and (3) in clear-cut cases of SWCs in patients with schizophrenia but without clinical seizures, a therapeutic trial with anticonvulsant medication might be warranted.

1 Huber G, Penin, H. Clinical-electroencephalographic correlation studies in schizophrenics [in German]. Fortschritte Neurol Psychiat 1968; 36: 641-59.

2 Slater E, Beard AW. The schizophrenia-like psychoses of epilepsy. V: Discussion and conclusions. Br J Psychiatry 1963; 109: 143-50.
3 Trimble MR, Schmitz B. Schizophrenia and other psychoses. In Epilepsy: A Comprehensive Textbook, Second Edition (Volume III) (eds Engel JR J, TA Pedley): 2113-21. Lippicott, Williams \& Wilkins, 2008.

4 Tucker GJ, D'Etre T, Harrow M, Galser GH. Behavior and symptoms of psychiatric patients and the electroencephalogram. Arch Gen Psychiatry 1965; 12: $278-86$

5 Walczak TS, Jayakar P. Interictal electroencephalography. In Epilepsy: A Comprehensive Textbook, Second Edition (Volume I) (eds Engel JR J, TA Pedley): 809-24. Lippicott, Williams \& Wilkins, 2010.

6 Galderisi S, Mucci A, Volpe U, Boutros N: Evidence-based medicine and electrophysiology in schizophrenia. Clin EEG Neurosci 2009; 40: 62-77.

Professor Dr Luder Tebartz van Elst, Department Director, Department of Psychiatry and Psychotherapy, Section for Experimental Neuropsychiatry, University Clinic Freiburg, Albert-Ludwigs-Universität Freiburg, Hauptstr. 5,

79104 Freiburg, Germany. Email: tebartzvanelst@uniklinik-freiburg.de;

Andreas Schulze-Bonhage, Dirk Altenmüller, Epilepsy Center, University Clinic Freiburg, Albert-Ludwigs-Universität Freiburg; Dieter Ebert, Department Director, Department of Psychiatry and Psychotherapy, Section for Experimental Neuropsychiatry, University Clinic Freiburg, Albert-Ludwigs-Universität Freiburg, Germany

doi: 10.1192/bjp.199.3.253a 